\title{
Fear and depression during the COVID-19 outbreak in Cameroon: a nation-wide observational study
}

Joseph Nelson Siewe Fodjo 1,2, Leonard Ngarka², Wepnyu Y. Njamnshi ${ }^{2,3}$, Leonard N. Nfor ${ }^{2}$, Michel K. Mengnjo ${ }^{2}$, Edwige Laure Mendoㄹ, Samuel A. Angwafor ${ }^{2}$, Jonas Guy Atchou Basseguin ${ }^{2}$, Cyrille Nkouonlack ${ }^{2}$, Edith N. Njit ${ }^{2}$, Nene Ahidjo², Eric S. Chokote², Fidèle Dema², Julius Y. Fonsah², Godwin Y. Tatah², Nancy Palmer², Paul F. Seke Etet ${ }^{2}$, Dennis Palmer ${ }^{2}$, Dickson S. Nsagha², Daniel E. Etya'ale ${ }^{3}$, Stephen Perrig ${ }^{3}$, Roman Sztajzel ${ }^{3}$, Jean-Marie Annoni ${ }^{3}$, Anne-Cécile Zoung-Kanyi Bissek ${ }^{4}$, Rose G. F. Leke ${ }^{2}$, Marie-Thérèse Abena Ondoa Obama ${ }^{2}$, John N. Nkengasong ${ }^{5}$, Robert Colebunders ${ }^{1}$ and Alfred K. Njamnshi ${ }^{2,3^{*}}$ (D)

\section{Abstract}

Background: The COVID-19 pandemic has been associated with significant psychological and social distress worldwide. We investigated fear and depression among adults in Cameroon during different phases of the COVID19 outbreak.

Methods: An online survey was conducted in Cameroon from June-December 2020 using a structured questionnaire. Socio-demographic data and information regarding COVID-19 history were obtained. Fear and depressive symptoms were assessed using the Fear of COVID-19 score (FCV-19S) and the Patient Health Questionnaire (PHQ-9), respectively. Responses were clustered in weeks to better appreciate their evolution over time.

Results: Overall, 7381 responses from all ten regions of Cameroon were analysed (median age: 30 years, $73.3 \%$ male). The prevalence of depression (PHQ-9 score $\geq 10$ ) was $8.4 \%$, and that of high fear of COVID-19 (FCV-19S scores $\geq 19$ ) was $57.4 \%$. These rates were similar across genders, age-groups, and region of residence. While mean weekly PHQ-9 scores remained fairly stable throughout the study period (range: $2.53-3.21 ; p=0.101$ ), mean FCV-19S scores were highest during the early weeks but decreased significantly thereafter (from 20.31 to 18.34; $p<0.001$ ). Multivariate analyses revealed that having a postgraduate degree, a history of quarantine, flu-like symptoms during the past 14 days, and higher FCV-19S scores were associated with more severe depressive symptoms, while obtaining COVID-19 information from various sources reduced the odds for depression.

Conclusion: Depression amidst the COVID-19 crisis is less prevalent in Cameroon than in other countries. Prompt and widespread dissemination of adequate COVID-19 information may reduce the risks for depression by dispelling fear and anxiety among Cameroonians.

Keywords: COVID-19, PHQ-9, FCV-19S, Cameroon, Fear, Depression

\footnotetext{
* Correspondence: alfred.njamnshi@brainafrica.org

${ }^{2}$ Brain Research Africa Initiative (BRAIN), Yaoundé, Cameroon

${ }^{3}$ Brain Research Africa Initiative (BRAIN), Geneva, Switzerland

Full list of author information is available at the end of the article
}

\section{$\triangle B M C$}

(c) The Author(s). 2021 Open Access This article is licensed under a Creative Commons Attribution 4.0 International License, which permits use, sharing, adaptation, distribution and reproduction in any medium or format, as long as you give appropriate credit to the original author(s) and the source, provide a link to the Creative Commons licence, and indicate if changes were made. The images or other third party material in this article are included in the article's Creative Commons. licence, unless indicated otherwise in a credit line to the material. If material is not included in the article's Creative Commons licence and your intended use is not permitted by statutory regulation or exceeds the permitted use, you will need to obtain permission directly from the copyright holder. To view a copy of this licence, visit http://creativecommons.org/licenses/by/4.0/ The Creative Commons Public Domain Dedication waiver (http://creativecommons.org/publicdomain/zero/1.0/) applies to the data made available in this article, unless otherwise stated in a credit line to the data. 


\section{Background}

Since its initial outbreak in China in December 2019, the coronavirus disease 2019 (COVID-19) has spread globally and caused over a million deaths [1]. Unprecedented restrictive measures were deployed by every nation to prevent or contain local epidemics. Besides the biological (and sometimes fatal) damages caused by the virus, the COVID-19 pandemic has been associated with significant psychological and social distress around the globe. Indeed, studies conducted during the COVID-19 pandemic have revealed high levels of stress, anxiety and depressive disorders among the general population [2], as well as specific populations: healthcare workers and their families [3-5], military personnel [6], and COVID19 survivors [7]. Available data suggests that women and younger individuals are more affected by psychosocial symptoms during the COVID-19 pandemic $[8,9]$. The socio-economic consequences of the strict lockdown measures implemented in many countries further exacerbated the financial insecurities of the population with adverse effects on their psychological and social wellbeing, leading to suicide in some cases [10].

Cameroon, a Low-Middle income country located in the Central African sub-region, was not spared by the COVID-19 pandemic. After reporting its first case on March 6th 2020, community transmission was observed resulting in a cumulative 26,277 cases and 448 deaths as of December 31st 2020 [11]. The necessary preventive measures prescribed by the Cameroonian government [12] have disrupted daily routines and adversely impacted the nation's socio-economic landscape given that a large proportion of the population relies on the informal sector for its livelihood. Although the mental or brain health impacts of the COVID-19 pandemic are evident in Cameroon [13], the magnitude of the problem is still poorly understood as no nation-wide study has yet been done. We therefore conducted this study to assess the level of fear and the frequency of depressive disorders in the Cameroonian population amidst the COVID19 outbreak. We further sought to identify determinants of fear and depressive symptoms during the ongoing health crisis.

\section{Methods}

\section{Study setting and population}

The study was conducted from June 5th to December 5th 2020, and recruited participants from all ten regions of Cameroon. Cameroon's population has a median age of 18.7 years and life expectancy of 60.3 years, with $56.3 \%$ of people living in urban settings [14]. For over 4 years, the nation has been confronted with an internal conflict in the two English-speaking regions (North West and South West) and sporadic terrorist attacks in the Northern part of the country.

\section{Study tools and procedures}

We performed online surveys designed by Brain Research Africa Initiative (BRAIN) researchers in collaboration with the International Citizen Project on COVID-19 (ICPCovid) consortium [15]. The ICPCovid website, initiated by a team of researchers based at the University of Antwerp in Belgium, offers a secure electronic platform to collect COVID-19-related data from several low- and middle-income countries in order to assess the population's perception of, and adherence to the implemented preventive measures. A web-based online questionnaire was designed using the 'Drupal' system, translated to English and French and pre-tested on Cameroonian adults. Besides collecting the socio-demographic information of participants, we also assessed their psychological and social well-being using two scales:

- Fear of COVID-19 scale (FCV-19S): This is a 7-item tool that was recently validated in Iran [16]. Each item on this scale is scored between 1 and 5. A total score is calculated by adding up each item score (overall score ranging from 7 to 35 ). The higher the score, the greater the fear of cororonavirus-19. A cut-off score of 19 and above on this scale has been suggested the identify individuals with a high level of COVID-19-related fear [17].

- Patient Health Questionnaire-9 (PHQ-9): This 9item tool was developed to screen for major depressive disorders among adults [18]. Each of the nine items is scored between 0 and 3 (maximum possible score: 27). Scores of 10 or above are often considered as an indication of a likely depressive disorder, as previously validated in a Cameroonian study population [19]. Other cut-offs have been proposed to further discriminate the severity of depressive symptoms: cut-off scores of $0-4=$ none $/$ minimal; $5-9=$ mild $; 10-14=$ moderate; $15-19=$ moderately severe; $20-27=$ severe $[3,17]$.

In addition to the above-mentioned screening tools, Likert-format questions were asked regarding the level of worry experienced by the respondents regarding their own health and the health of their loved ones during the COVID-19 crisis; this was expressed on a 5-point scale ranging from 1 (not at all worried) to 5 (extremely worried). The web-link to the electronic survey was disseminated via social media platforms and bulk messaging to phone users. Upon clicking on the link, the user was directed to an information and consent page where he/she could agree to participate, fill in the responses submit them via a smartphone, tablet, or computer. The electronic questionnaire was made accessible during certain periods each month, and closed down intermittently between survey rounds. All submitted responses were 
immediately stored in a password-protected server in Belgium until data retrieval.

\section{Data analysis}

Collected data were exported to Microsoft Excel 2016 spreadsheets for cleaning, and later transferred to $\mathrm{R}$ version 4.0.2 for analysis. Based on the fact that continuous variables were not normally distributed as shown by the Kolgomorov-Smirnov test, we summarized them as median with interquartile range (IQR). On the other hand, categorical variables were expressed as fractions and percentages. To investigate determinants of depressive symptoms as screened by the PHQ- 9 tool, an ordinal logistic regression model was constructed with the different severity levels of depression (none/minimal, mild, moderate, moderately severe, severe) as dependent variable and socio-demographic variables as covariates. To capture the effect of the ongoing armed conflicts in some parts of the country, a binary variable was created as follows: conflictstricken region $=$ yes (for respondents residing in the Far North, North West, and South West regions) vs no (for all other regions). Given the prolonged study period and the rapid evolution of COVID-19 dynamics, we took into account the timing of the responses by considering the different study weeks as clusters. Only weeks with $\geq 100$ responses were included in the multivariate analysis. We used the polr function (package: 'MASS') and the vcovCL function (package: 'sandwich') in the software R to obtain clustered standard errors from the regression model. Covariates for the final model were selected based on a $p$-value $<0.2$ during univariate analysis.

\section{Results}

Of the 7538 responses received, 7381 were eligible for analysis (median age: 30 years, 73.3\% male); Table 1. About one-fifth of the participants $(n=1454 ; 19.7 \%)$ resided in the conflict-stricken regions of Cameroon. Majority of participants (70.9\%) had attained university level of education.

The median PHQ-9 score in our study population was 1.0 (IQR: $0-4$ ) on a scale ranging from 0 to 21 . Using the PHQ-9 cut-off value of $\geq 10$ as positive screening for depression, the prevalence of depression was $617 / 7381$ (8.4\%). Applying the other cut-offs revealed the frequencies of no/minimal, mild, moderate, moderately severe, and severe depression to be respectively: 5669 (76.8\%), 1095 (14.8\%), 346 (4.7\%), 178 (2.4\%), and 93 (1.3\%). Regarding COVID-19 fear, FCV-19S scores ranged from 7 to 35 , with median 20 (IQR: $15-23$ ) and mean $19.3 \pm 6.4$. Furthermore, more than half of the respondents $(n=$ 4238; 57.4\%) reported experiencing high levels of fear (i.e. FCV-19S scores $\geq 19$ ). The prevalence of both depression (PHQ-9 score $\geq 10$ ) and high level of fear (FCV$19 \mathrm{~S} \geq 19)$ were similar across genders, age groups,
Table 1 Participants' characteristics

\begin{tabular}{|c|c|}
\hline Characteristics & $\begin{array}{l}\text { Survey } \\
\text { findings } \\
N=7381\end{array}$ \\
\hline Age: Median [IQR] & $\begin{array}{l}30.0(25.0- \\
38.0)\end{array}$ \\
\hline \multicolumn{2}{|l|}{ Gender: n (\%) } \\
\hline Male & $5409(73.3 \%)$ \\
\hline Female & $1972(26.7 \%)$ \\
\hline \multicolumn{2}{|l|}{ Highest educational level: n (\%) } \\
\hline Primary school & $118(1.6 \%)$ \\
\hline Secondary school & $2029(27.5 \%)$ \\
\hline University: Undergraduate & $2963(40.1 \%)$ \\
\hline University: Postgraduate & $2271(30.8 \%)$ \\
\hline \multicolumn{2}{|l|}{ Residential setting: n (\%) } \\
\hline Rural & $672(9.1 \%)$ \\
\hline Sub-Urban & $1327(18.0 \%)$ \\
\hline Urban & $5382(72.9 \%)$ \\
\hline Living alone in household: $\mathrm{n}(\%)$ & $1383(18.7 \%)$ \\
\hline \multicolumn{2}{|l|}{ Self-reported socio-economic status: n (\%) } \\
\hline Low class & $2494(33.8 \%)$ \\
\hline Lower-middle class & $3839(52.0 \%)$ \\
\hline Upper-middle class & $912(12.4 \%)$ \\
\hline High class & $136(1.8 \%)$ \\
\hline \multicolumn{2}{|l|}{ Profession: n (\%) } \\
\hline Student & $1832(24.8 \%)$ \\
\hline Unemployed & $1342(18.2 \%)$ \\
\hline Self-employed & $869(11.8 \%)$ \\
\hline Private employee & $1843(25.0 \%)$ \\
\hline Government employee & $1285(17.4 \%)$ \\
\hline Retired & $210(2.9 \%)$ \\
\hline Healthcare worker or student: $\mathrm{n}(\%)$ & $793(10.7 \%)$ \\
\hline \multicolumn{2}{|l|}{ Source of COVID-19 information: $n(\%)^{a}$} \\
\hline Radio, Television, or government announcements & $6601(89.4 \%)$ \\
\hline Social Media & $5780(78.3 \%)$ \\
\hline Healthcare worker & $2874(38.9 \%)$ \\
\hline Underlying chronic disease: $\mathrm{n}(\%)^{\mathrm{b}}$ & $716(9.7 \%)$ \\
\hline History of being quarantined at home/institution: $\mathrm{n}(\%)$ & $1375(18.6 \%)$ \\
\hline $\begin{array}{l}\text { History of violence/discrimination during COVID-19 out- } \\
\text { break: } \mathrm{n}(\%)\end{array}$ & $1334(18.1 \%)$ \\
\hline
\end{tabular}

residential setting, being in the healthcare sector or not, and region of residence (Table 2).

FCV-19S scores correlated significantly with PHQ-9 scores (Spearman-rho $=0.28, p<0.001$ ). Considering only weeks with at least 100 responses, both COVID-19 
Table 2 Prevalence of depression and high fear levels during the COVID-19 outbreak in Cameroon

\begin{tabular}{|c|c|c|c|c|c|}
\hline Characteristics & & $F C V-19 S \geq 19:$ n (\%) & $P$-value ${ }^{a}$ & $\begin{array}{l}\text { PHQ-9 score } \geq 10 \text { : } \\
\text { n (\%) }\end{array}$ & $P$-value ${ }^{a}$ \\
\hline \multirow[t]{2}{*}{ Gender } & Male & 3079 (56.9\%) & 0.163 & $458(8.5 \%)$ & 0.611 \\
\hline & Female & 1159 (58.8\%) & & 159 (8.1\%) & \\
\hline \multirow[t]{5}{*}{ Age } & $18-25$ years & 1186 (56.7\%) & 0.289 & $185(8.8 \%)$ & 0.588 \\
\hline & $26-35$ years & $1724(57.4 \%)$ & & $254(8.5 \%)$ & \\
\hline & $36-45$ years & $750(56.4 \%)$ & & $104(7.8 \%)$ & \\
\hline & $46-55$ years & $365(60.9 \%)$ & & $51(8.5 \%)$ & \\
\hline & $>55$ years & $213(60.0 \%)$ & & $23(6.5 \%)$ & \\
\hline \multirow[t]{10}{*}{ Region } & Centre & $1267(57.8 \%)$ & 0.758 & 178 (8.1\%) & 0.773 \\
\hline & Adamawa & $183(57.4 \%)$ & & 29 (9.1\%) & \\
\hline & East & 101 (55.8\%) & & $9(5.0 \%)$ & \\
\hline & Far North & 247 (58.1\%) & & $43(10.1 \%)$ & \\
\hline & Littoral & 1006 (57.0\%) & & $147(8.3 \%)$ & \\
\hline & North & $131(55.3 \%)$ & & 19 (8.0\%) & \\
\hline & North West & $414(56.6 \%)$ & & $67(9.2 \%)$ & \\
\hline & South & 129 (54.9\%) & & $18(7.7 \%)$ & \\
\hline & South West & 440 (60.9\%) & & $59(8.2 \%)$ & \\
\hline & West & $320(55.8 \%)$ & & $48(8.4 \%)$ & \\
\hline \multirow[t]{3}{*}{ Residential setting } & Rural & 374 (55.7\%) & 0.624 & $51(7.6 \%)$ & 0.646 \\
\hline & Sub-urban & 765 (57.6\%) & & 107 (8.1\%) & \\
\hline & Urban & 3099 (57.6\%) & & $459(8.5 \%)$ & \\
\hline \multirow[t]{2}{*}{ Worker/student in healthcare } & Yes & $432(54.5 \%)$ & 0.083 & $67(8.5 \%)$ & 0.977 \\
\hline & No & $3806(57.8 \%)$ & & $550(8.4 \%)$ & \\
\hline
\end{tabular}

${ }^{a}$ Chi-Squared test

fear and PHQ-9 scores seemed to increase with increasing weekly incidence of COVID-19 in Cameroon, and vice versa (Fig. 1). While the COVID-19 weekly incidence in Cameroon did not correlate significantly with the respondents' FCV-19S scores (Spearman-rho $=0.021$, $p=0.078$ ), a weak positive correlation was found between weekly COVID-19 incidence and PHQ-9 scores (Spearman-rho $=0.033, p=0.006$ ). Mean weekly PHQ-9 scores did not vary significantly across the study period (range: $2.53-3.21 ; p=0.101$ ), in contrast to mean FCV$19 \mathrm{~S}$ scores which were highest during the early weeks of the survey but decreased significantly thereafter (range: 18.34-20.31; $p<0.001)$. The median Likert score for worrying about other people's health was significantly higher than that of worrying for one's own health: 1 (IQR: $1-3)$ vs 1 (IQR: $1-2$ ), $p<0.001$.

Using dichotomized PHQ-9 and FCV-19S scores, we estimated the prevalence of depression and high fear for the study weeks with $\geq 100$ responses (Table 3 ). We observed similar proportions of respondents with depression across the different study weeks $(p=0.195)$, while there were significant differences in the prevalence of high fear $(p<0.001)$.
The multivariate analysis revealed that having a postgraduate degree, a history of quarantine, experiencing flulike symptoms during the past 14 days, and higher FCV195 scores were associated with increased odds to have more severe depressive symptoms. Meanwhile, obtaining COVID-19 information from either official sources or from the social media reduced these odds (Table 4).

\section{Discussion}

Our study is the first to assess fear and depression among Cameroonian adults during 6 months of the COVID-19 crisis, in a nation-wide large survey. Overall, almost one-tenth of respondents screened positive for depression and the PHQ-9 depression scores appeared to vary proportionately to the weekly incidence of COVID-19. It is worth noting that during the latter months of the study period, schools were allowed to resume cautiously and this brought about a semblance of normalcy in the daily routines of Cameroonians. These changes may have had repercussions on the overall psychosocial well-being of the study participants over time.

The prevalence of depression during the COVID-19 crisis in our study is lower compared to previous reports 


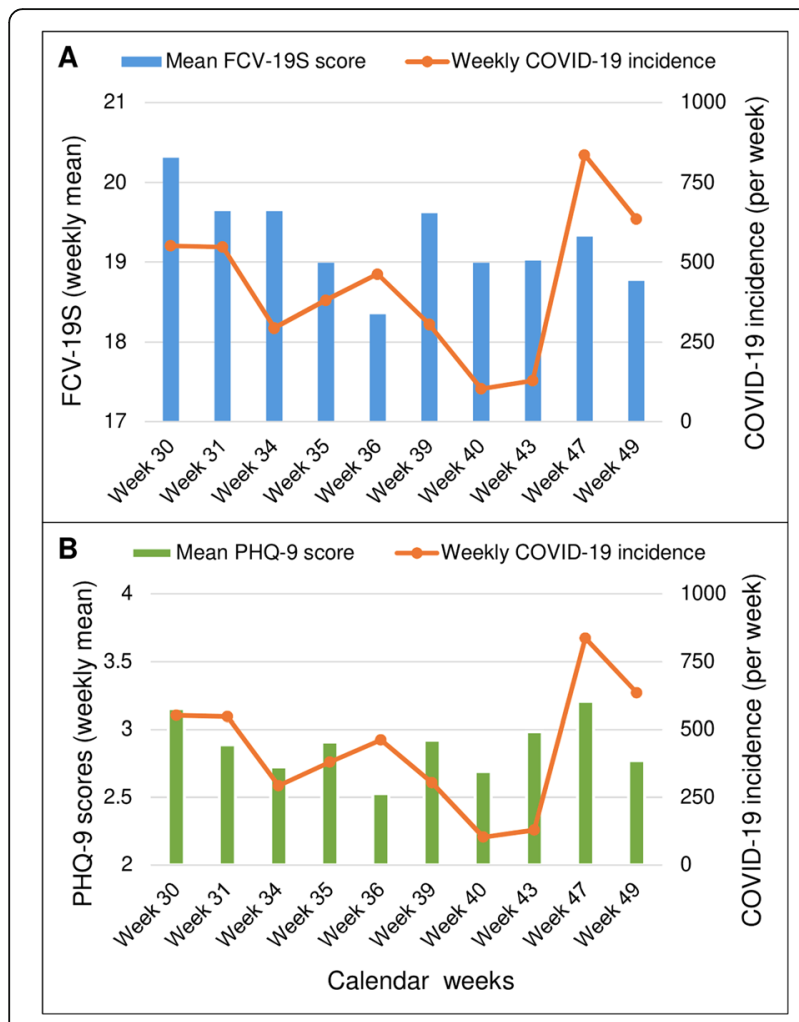

Fig. 1 Weekly evolution of COVID-19 incidence and: A Fear scores; B PHQ-9 scores

by researchers who also used the PHQ-9 tool with a cutoff score of $\geq 10$ in both high-income and low- middleincome countries [17, 20-22]. Our numbers are also lower than pre-COVID-19 depression rates in healthy Cameroonian adults, estimated at $19.8 \%$ in one study [23] but the fact that a different screening tool (Beck's Depression Inventory) was used renders comparisons with our study difficult. It is expected that the COVID-19 pandemic would cause a rise in the burden of depression compared to baseline levels, as observed during a comparative study in American adults [24]. Of note, pre-COVID-19 depression levels were already low in Africa compared to other continents (except for Australia) [25], and the pandemic would likely exacerbate existing situations without necessarily altering the global distribution of depressive disorders. Furthermore, in resource-limited settings such as Cameroon where economic hardship is frequent, lower depression rates may also be observed because people are more focused on being financially productive amidst the crisis to keep providing for their families, even to the point of overlooking or mentally downplaying the threat of COVID-19. This notwithstanding, the most educated respondents (post-graduate level) who probably had a better understanding of the COVID-19 science and the risks associated with the pandemic were prone to more severe depressive symptoms (adjusted odds ratio of 1.5, relative to respondents with primary level education).

Regarding FCV-19S results, over half of the participants experienced high levels of fear vis-à-vis COVID19. This is greater than the $35.7 \%$ reported in Greece [17] using a similar methodology. COVID-19 fear scores were highest at the beginning of the study period (June 2020), possibly because that period represented the first epidemic peak in Cameroon with thousands of cases confirmed on a weekly basis. No regional disparity was noted in the prevalence of depression or high fear of COVID-19. This is an intriguing finding, because we expected that persons residing in conflict-stricken regions would experience more psychological and social distress in the face of the COVID-19 outbreak. Qualitative research may be required to better understand the determinants of mental and brain health, as well as the coping mechanisms of individuals in different settings during the COVID-19 pandemic.

Table 3 Prevalence of depression and high fear across the study weeks

\begin{tabular}{|c|c|c|c|c|}
\hline Calendar week & $\begin{array}{l}\text { High fear } \\
\text { (FCV-19S } \geq 19) \text { : } \\
\text { n (\%) }\end{array}$ & $P$-value ${ }^{a}$ & $\begin{array}{l}\text { Depression } \\
\text { (PHQ-9 score } \geq 10) \text { : } \\
\text { n (\%) }\end{array}$ & $P$-value ${ }^{\mathrm{a}}$ \\
\hline Week $30(n=817)$ & $517(63.3 \%)$ & \multirow[t]{10}{*}{$<0.001$} & $74(9.1 \%)$ & \multirow[t]{10}{*}{0.195} \\
\hline Week $31(n=286)$ & $167(58.4 \%)$ & & 27 (9.4\%) & \\
\hline Week $34(n=1132)$ & $677(59.8 \%)$ & & $84(7.4 \%)$ & \\
\hline Week $35(n=120)$ & 68 (56.7\%) & & $11(9.2 \%)$ & \\
\hline Week $36(n=640)$ & $333(52.0 \%)$ & & $32(5.0 \%)$ & \\
\hline Week $39(n=152)$ & 90 (59.2\%) & & $14(9.2 \%)$ & \\
\hline Week $40(n=454)$ & $248(54.6 \%)$ & & $36(7.9 \%)$ & \\
\hline Week $43(n=1686)$ & $940(55.8 \%)$ & & 159 (9.4\%) & \\
\hline Week $47(n=1347)$ & $785(58.3 \%)$ & & $132(9.8 \%)$ & \\
\hline Week $49(n=397)$ & $216(54.4 \%)$ & & $26(6.6 \%)$ & \\
\hline
\end{tabular}

${ }^{\mathrm{a} C h i}$ squared test 
Table 4 Clustered ordinal logistic regression investigating factors associated with increasing severity of depressive symptoms

\begin{tabular}{|c|c|c|c|}
\hline Covariates & Univariate $P$-value & $\begin{array}{l}\text { Adjusted OR } \\
(95 \% \mathrm{Cl})\end{array}$ & $\begin{array}{l}\text { Multivariate } \\
P \text {-value }\end{array}$ \\
\hline Age (in years) & 0.099 & $0.994(0.986-1.003)$ & 0.177 \\
\hline \multicolumn{4}{|l|}{ Socioeconomic status: } \\
\hline Low & Ref & Ref & \\
\hline Lower middle & 0.097 & $1.137(0.991-1.305)$ & 0.066 \\
\hline Upper middle & 0.809 & $1.041(0.853-1.269)$ & 0.694 \\
\hline High & 0.117 & $1.300(0.853-1.980)$ & 0.222 \\
\hline \multicolumn{4}{|l|}{ Educational level } \\
\hline Primary & Ref & Ref & \\
\hline Secondary & 0.337 & $1.354(0.914-2.006)$ & 0.131 \\
\hline Undergraduate & 0.247 & 1.388 (0.919-2.097) & 0.119 \\
\hline Postgraduate & 0.141 & $1.523(1.011-2.294)$ & 0.044 \\
\hline \multicolumn{4}{|l|}{ Profession } \\
\hline Student & Ref & Ref & \\
\hline Jobless & 0.767 & $1.026(0.877-1.201)$ & 0.746 \\
\hline Self-employed & 0.173 & $0.974(0.787-1.205)$ & 0.808 \\
\hline Private worker & 0.850 & $1.022(0.928-1.127)$ & 0.655 \\
\hline Government worker & 0.614 & $0.953(0.819-1.107)$ & 0.526 \\
\hline Retired & 0.914 & $1.210(0.727-2.013)$ & 0.463 \\
\hline Student / worker in healthcare sector & 0.159 & $1.095(0.958-1.252)$ & 0.185 \\
\hline COVID-19 information from official sources (TV, radio, or other government channels) & 0.011 & $0.801(0.728-0.882)$ & $<0.001$ \\
\hline COVID-19 information from social media & 0.078 & $0.831(0.758-0.912)$ & $<0.001$ \\
\hline Living alone in household & 0.132 & $1.098(0.986-1.224)$ & 0.089 \\
\hline Flu-like symptoms during the past 14 days & $<0.001$ & $2.296(2.050-2.570)$ & $<0.001$ \\
\hline History of quarantine/isolation for COVID-19 & $<0.001$ & $1.568(1.422-1.728)$ & $<0.001$ \\
\hline History of violence/discrimination & 0.182 & $0.949(0.816-1.104)$ & 0.501 \\
\hline Fear of COVID-19 score & $<0.001$ & $1.114(1.102-1.127)$ & $<0.001$ \\
\hline Residential setting & & - & - \\
\hline Rural & Ref & & \\
\hline Sub-urban & 0.639 & & \\
\hline Urban & 0.567 & & \\
\hline COVID-19 information from healthcare workers & 0.929 & - & - \\
\hline Male gender & 0.459 & - & - \\
\hline Conflict-stricken region & 0.329 & - & - \\
\hline
\end{tabular}

OR Odd's ratio, $\mathrm{Cl}$ Confidence interval, Ref Reference category

The frequency of depression and high fear of COVID19 was similar among participants who were workers/ students in the healthcare sector and others not involved in healthcare. A possible explanation for this observation is the reduced exposure to COVID-19 patients for health personnel in Cameroon due to a relatively lower COVID-19 burden compared to other regions of the world. Indeed, increased exposure to COVID-19 cases has been shown to fuel stress, anxiety and depression among healthcare providers [26]. Therefore, it is understandable that mental and brain disorders during the COVID-19 pandemic may be more frequent among healthcare workers in Europe, America, Asia [3, 6, 2729], but also in neighbouring Nigeria [30] which has more than thrice the number of COVID-19 cases in Cameroon [1]. It is worth noting that another survey previously conducted among healthcare workers in Cameroon during the COVID-19 pandemic found a prevalence of depression of $42.8 \%$ using the Hospital Anxiety and Depression scale (HADS) [31], compared to 
$8.5 \%$ in our study. While acknowledging the methodological differences between our study and the aforementioned survey, their findings do suggest that exposure of healthcare workers to COVID-19 patients is an important stressor in Cameroon. The authors reported that fear of contamination with the coronavirus and fear of death were modulators of depression among the health personnel [31].

Participants with a history of quarantine, or those who had recently experienced flu-like symptoms (during the past 2 weeks) were more likely to exhibit depressive symptoms. These results concur with observations made in Canada during the SARS-1 outbreak during which longer quarantine durations and a history of contact with an infected person were associated with increased psychological distress [32]. Similar observations were made in Brazil and Portugal during the COVID-19 pandemic [33]. This highlights quarantine / isolation as a risk factor for short- and possibly long-term psychosocial distress, requiring careful consideration by the health authorities [34]. We observed that during the COVID-19 outbreak in Cameroon, the respondents were more concerned about the health of their loved ones than their own health. This finding is relevant in the context of implementing public health measures such as mandatory quarantine and vaccination for COVID-19. Although adherence to preventive measures may depend more on their practicality (ease of implementation) than on the psychology of individuals [35], one could still appeal to altruism by reminding the public about the community-wide benefits of such interventions. It is clear the impact of the interventions goes beyond individual protection to shielding other community members from becoming infected. In a situation whereby even healthcare workers are against a vaccine trial in their community [36], it is important to emphasize the collective benefits of vaccination while rendering the process of COVID-19 vaccination as simple and attractive as possible in a bid to improve acceptability. Studies on attitudes and acceptability of the COVID-19 vaccine in Cameroon are needed.

Participants who resorted to various platforms (radio, television, government announcements, or social media) in search of information about COVID-19 had reduced odds of experiencing depressive symptoms. Similar findings were reported by González-Sanguino et al. in Spain, as they found a negative relationship between depression and having adequate information about the coronavirus [9]. Meanwhile, a study conducted among Chinese adults during their nationwide lockdown showed that a higher level of COVID-19 media exposure was significantly associated with higher PHQ-9 scores [37]. We surmise that the information from various media rather produced a soothing effect on Cameroonian participants by unveiling how grave the COVID-19 situation was in other countries, and providing a sense of relative safety. Indeed, the COVID-19 burden and death toll in Cameroon is considerably lower compared to the daily reports from Europe and the Americas [38]. It is expedient that the media outlets be leveraged to promptly disseminate adequate COVID-19-related information to the public, as this approach is a pillar in ensuring optimal mental and brain health during such health crises by addressing any sense of uncertainty and fear [39].

A number of limitations must be taken into account when interpreting our study findings. This was an online survey, and it is therefore impossible to verify the veracity of the provided responses. In addition, we acknowledge a sampling bias since our survey could only be filled by literate and educated individuals who had access to internet. Indeed, the web-based recruitment procedures could not achieve a representative study population. Fewer female respondents participated in the survey; this could be due to the fact that in Cameroon, it was reported that women are less likely to use the internet compared to men [40]. After the preliminary data analysis, an effort was made through the Ministry of Women's Empowerment and the Family to encourage more women in women's groups to participate but the percentage increase in participation was just 1.5 (from 25.2 to 26.7). Since the female gender has been associated with greater psychological distress during the COVID-19 outbreak [9], the male predominance in our study population might have led to an underestimation of the overall burden of COVID-19-related fear and depression in Cameroon. Lastly, the survey's duration was very long, considering the rapidly evolving dynamics of COVID-19 and could lead to participant fatigue. However, this was mitigated by constituting weekly clusters during the data analysis.

\section{Conclusions}

Our study found that less than $10 \%$ of Cameroonian adults reported depressive symptoms amidst the COVID-19 crisis, much lower than what has been documented in other settings. Meanwhile, over half of the respondents experienced a high level of fear of COVID-19. We recommend that various media outlets should be leveraged to disseminate adequate information about COVID-19 as this will dispel fear and reduce the risk for depression. Furthermore, persons who report flu-like symptoms, the more educated individuals (postgraduates) and those who had been quarantined seem to be at increased risk for depression, and should be prioritized for interventions during the COVID-19 pandemic in Cameroon. Finally, appealing to the population's sense of altruism may be the way forward to ensure optimal 
mental and brain health, as well as better acceptability of large scale COVID-19 preventive measures.

\section{Abbreviations}

COVID-19: Coronavirus disease 2019; FCV-19S: Fear of COVID-19 score; ICPCovid: International Citizen Project on COVID-19; IQR: Interquartile range; PHQ-9: Patient Health Questionnaire

\section{Acknowledgements}

We are grateful to the Cameroon Prime Minister's Office for overall administrative support, the Ministry of Communication and the Ministry of Post and Telecommunications of Cameroon and its partners for assisting in sensitisation of the population and in disseminating the survey link. We appreciate the Ministry of Women's Empowerment and the Family for sensitisation through women's organisations. We sincerely thank the participants for providing the responses.

\section{Authors' contributions}

SFJN, CR, and NAK conceived the study. NAK obtained administrative support/ethical clearance in Cameroon and supervised the entire project. NL, NWY, LNN MMK and MEL coordinated data collection. ASA, ABJG, NC, NEN, AN, CES, DF, FJY, TGY, PN, SEPF, PD, NDS, EDE, PS, SR, AJM, Z-KBAC, LRGF, AOOMT \& NNJ contributed to adaptation of research instrument to the Cameroonian context and coordinated sensitisation (through national, regional and social media) and data collection coordination at national and/or regional levels. SFJN cleaned and analysed the data, and drafted the initial manuscript. All authors critically reviewed the draft and approved the final manuscript.

\section{Funding}

The study was supported by a grant from the European Research Counci (ERC 671055) and VLIRUOS (the Flemish University cooperation). The study sponsors had no role in the study design; in the collection, analysis, and interpretation of data; in the writing of the manuscript; and in the decision to submit the paper for publication.

\section{Availability of data and materials}

All the data presented in this article are available upon reasonable request from the ICPcovid consortium: icpcovid@uantwerpen.be

\section{Declarations}

\section{Ethics approval and consent to participate}

This study was approved by the National Ethics Committee of Cameroon (Ref: 2020/05/1229/CE/CNERSH/SP of 06th May 2020) as well as the Ethics Committee of the University of Antwerp, Belgium (Ref: 20/13/148). All procedures were in accordance with international research guidelines. Only data from participants aged at least 18 years and who provided an informed e-consent were retained for analysis. All data were collected anonymously and treated with absolute confidentiality.

\section{Consent for publication}

Not applicable.

\section{Competing interests}

The authors have no conflicts of interest to declare.

\section{Author details}

'Global Health Institute, University of Antwerp, Antwerp, Belgium. ${ }^{2}$ Brain Research Africa Initiative (BRAIN), Yaoundé, Cameroon. ${ }^{3}$ Brain Research Africa Initiative (BRAIN), Geneva, Switzerland. ${ }^{4}$ Division of Health Operations Research, Ministry of Public Health, Yaoundé, Cameroon. ${ }^{5} \mathrm{CDC}$ Africa, African Union, Addis Ababa, Ethiopia.

Received: 28 January 2021 Accepted: 24 May 2021 Published online: 15 July 2021

\section{References}

1. WHO Coronavirus Disease (COVID-19) Dashboard [Internet]. [cited 2021 Apr 1]. Available from: https://covid19.who.int
2. Salari N, Hosseinian-Far A, Jalali R, Vaisi-Raygani A, Rasoulpoor S, Mohammadi $\mathrm{M}$, et al. Prevalence of stress, anxiety, depression among the general population during the COVID-19 pandemic: a systematic review and meta-analysis. Glob Health. 2020;16(1):57. https://doi.org/10.1186/s12 992-020-00589-w.

3. Kapila AK, Ram A, D'Uva L, Farid Y, Talib M. The importance of assessing the self-reported impact of COVID-19 on clinician mental health. Eur J Psychiatry. 2020;34(4):223-4. https://doi.org/10.1016/j.ejpsy.2020.06.002.

4. Keubo FRN, Mboua PC, Tadongfack TD, Tchoffo EF, Tatang CT, Zeuna Jl, et al. Psychological distress among health care professionals of the three COVID-19 most affected regions in Cameroon: prevalence and associated factors. Ann Med Psychol (Paris). 2021;179(2):141-6. https://doi.org/10.1016/ j.amp.2020.08.012

5. Ying Y, Ruan L, Kong F, Zhu B, Ji Y, Lou Z. Mental health status among family members of health care workers in Ningbo, China, during the coronavirus disease 2019 (COVID-19) outbreak: a cross-sectional study. BMC Psychiatry. 2020;20(1):379. https://doi.org/10.1186/s12888-020-02784-w.

6. Pan X, Xiao Y, Ren D, Xu Z, Zhang $Q$, Yang $L$, et al. Prevalence of mental health problems and associated risk factors among military healthcare workers in specialized COVID-19 hospitals in Wuhan, China: A crosssectional survey. Asia-Pac Psychiatry. 2020; [cited 2020 Nov 17]; Available from: https://onlinelibrary.wiley.com/doi/10.1111/appy.12427.

7. Taquet M, Luciano S, Geddes JR, Harrison PJ. Bidirectional associations between COVID-19 and psychiatric disorder: retrospective cohort studies of 62354 COVID-19 cases in the USA. Lancet Psychiatry. 2021;8(2):130-40. https://doi.org/10.1016/S2215-0366(20)30462-4

8. Losada-Baltar A, Martínez-Huertas JÁ, Jiménez-Gonzalo L, del SM P-C, Gallego-Alberto L, Fernandes-Pires J, et al. Longitudinal Correlates of Loneliness and Psychological Distress During the Lockdown Situation due to COVID-19. Effects of Age and Self-Perceptions of Aging. J Gerontol Series B. 2021;gbab012.

9. González-Sanquino C, Ausín B, Castellanos MÁ, Saiz J, López-Gómez A Ugidos $C$, et al. Mental health consequences during the initial stage of the 2020 coronavirus pandemic (COVID-19) in Spain. Brain Behav Immun. 2020; 87:172-6. https://doi.org/10.1016/j.bbi.2020.05.040

10. AKMI B, Sakib N, Pakpour AH, Griffiths MD, Mamun MA. COVID-19-Related Suicides in Bangladesh Due to Lockdown and Economic Factors: Case Study Evidence from Media Reports. Int J Ment Health Addict. 2020; [cited 2020 Nov 17]; Available from: http://link.springer.com/10.1007/s11469-020-00307-y.

11. Cameroon: WHO Coronavirus Disease (COVID-19) Dashboard [Internet]. [cited 2021 Jan 2]. Available from: https://covid19.who.int

12. Government response strategy to the Coronavirus pandemic (COVID-19) | Prime Minister's Office [Internet]. [cited 2020 Nov 1]. Available from: https:// www.spm.gov.cm/site/?q=en/content/government-response-strategycoronavirus-pandemic-covid-19

13. Mviena JLM, Fanne M, Gondo R, Mwamelo AJ, Esso L, Epée E, et al. How mental health care is changing in Cameroon because of the COVID-19 pandemic. Lancet Psychiatry. 2020;7(10):e62-3. https://doi.org/10.1016/S221 5-0366(20)30390-4

14. Cameroon Population (2020) - Worldometer. [cited 2020 Nov 17]. Available from: https://www.worldometers.info/world-population/cameroon-population/

15. ICPCovid research group. International Citizen Project Covid-19. 2020 [cited 2020 May 11]. Available from: https://www.icpcovid.com/

16. Ahorsu DK, Lin C-Y, Imani V, Saffari M, Griffiths MD, Pakpour AH. The Fear of COVID-19 Scale: Development and Initial Validation. Int J Ment Health Addict. 2020; [cited 2020 Apr 16]; Available from: http://link.springer.com/1 0.1007/s11469-020-00270-8.

17. Parlapani E, Holeva V, Voitsidis P, Blekas A, Gliatas I, Porfyri GN, et al. Psychological and behavioral responses to the COVID-19 pandemic in Greece. Front Psychiatry. 2020;11:821. https://doi.org/10.3389/fpsyt.2020. 00821.

18. Kroenke K, Spitzer RL, Williams JBW. The patient health Questionnaire-2: validity of a two-item depression screener. Med Care. 2003;41(11):1284-92. https://doi.org/10.1097/01.MLR.0000093487.78664.3C.

19. Pence BW, Gaynes BN, Atashili J, O’Donnell JK, Tayong G, Kats D, et al. Validity of an interviewer-administered patient health questionnaire-9 to screen for depression in HIV-infected patients in Cameroon. J Affect Disord. 2012:143(1-3):208-13. https://doi.org/10.1016/j.jad.2012.05.056.

20. Ueda M, Stickley A, Sueki H, Matsubayashi T. Mental health status of the general population in Japan during the COVID-19 pandemic. Psychiatry Clin Neurosci. 2020;74(9):505-6. https://doi.org/10.1111/pcn.13105. 
21. Sigdel A, Bista A, Bhattarai N, Pun BC, Giri G, Marqusee H, et al. Depression, anxiety and depression-anxiety comorbidity amid COVID-19 pandemic: an online survey conducted during lockdown in Nepal: Public and Global Health; 2020. Available from: http://medrxiv.org/lookup/doi/10.1101/2020. 04.30 .20086926

22. Choi EPH, Hui BPH, Wan EYF. Depression and anxiety in Hong Kong during COVID-19. Int J Environ Res Public Health. 2020;17(10):3740. https://doi.org/1 0.3390/ijerph17103740

23. Kanmogne GD, Qiu F, Ntone FE, Fonsah JY, Njamnshi DM, Kuate CT, et al. Depressive symptoms in HIV-infected and seronegative control subjects in Cameroon: Effect of age, education and gender. PLOS ONE. 2017;12: e0171956.

24. Ettman CK, Abdalla SM, Cohen GH, Sampson L, Vivier PM, Galea S Prevalence of depression symptoms in US adults before and during the COVID-19 pandemic. JAMA Netw Open. 2020;3(9):e2019686. https://doi. org/10.1001/jamanetworkopen.2020.19686.

25. Lim GY, Tam WW, Lu Y, Ho CS, Zhang MW, Ho RC. Prevalence of depression in the community from 30 countries between 1994 and 2014. Sci Rep. 2018; 8(1):2861. https://doi.org/10.1038/s41598-018-21243-x.

26. Kannampallil TG, Goss CW, Evanoff BA, Strickland JR, McAlister RP, Duncan J. Exposure to COVID-19 patients increases physician trainee stress and burnout. PLOS ONE. 2020;15:e0237301.

27. Khanal P, Devkota N, Dahal M, Paudel K, Joshi D. Mental health impacts among health workers during COVID-19 in a low resource setting: a crosssectional survey from Nepal. Glob Health. 2020;16(1):89. https://doi.org/10.11 86/s12992-020-00621-z

28. Vizheh M, Qorbani M, Arzaghi SM, Muhidin S, Javanmard Z, Esmaeili M. The mental health of healthcare workers in the COVID-19 pandemic: a systematic review. J Diabetes Metab Disord. 2020;26;19(2):1-12. https://doi. org/10.1007/s40200-020-00643-9.

29. Pearman A, Hughes ML, Smith EL, Neupert SD. Mental health challenges of United States healthcare professionals during COVID-19. Front Psychol. 2020;11:2065. https://doi.org/10.3389/fpsyg.2020.02065.

30. Agberotimi SF, Akinsola OS, Oguntayo R, Olaseni AO. Interactions between socioeconomic status and mental health outcomes in the Nigerian context amid COVID-19 pandemic: a comparative study. Front Psychol. 2020;11: 559819. https://doi.org/10.3389/fpsyg.2020.559819.

31. Mboua CP, Keubo FRN, Fouaka SGN. Anxiété et dépression associées à la prise en charge de la COVID-19 chez les personnels de santé au Cameroun. Evol Psychiatr (Paris). 2021;86(1):131-9.

32. Hawryluck L, Gold WL, Robinson S, Pogorski S, Galea S, Styra R. SARS control and psychological effects of quarantine, Toronto, Canada. Emerg Infect Dis. 2004;10(7):1206-12. https://doi.org/10.3201/eid1007.030703.

33. Passos L, Prazeres F, Teixeira A, Martins C. Impact on mental health due to COVID-19 pandemic: cross-sectional study in Portugal and Brazil. Int J Environ Res Public Health. 2020;17(18):6794. https://doi.org/10.3390/ijerph1 7186794.

34. Brooks SK, Webster RK, Smith LE, Woodland L, Wessely S, Greenberg N, et al. The psychological impact of quarantine and how to reduce it: rapid review of the evidence. Lancet. 2020;395(10227):912-20. https://doi.org/10.1016/ S0140-6736(20)30460-8.

35. Reicher S, Drury J. Pandemic fatigue? How adherence to covid-19 regulations has been misrepresented and why it matters. BMJ. 2021; [cited 2021 Apr 27]. Available from: https://blogs.bmj.com/bmj/2021/01/07/pa ndemic-fatigue-how-adherence-to-covid-19-regulations-has-beenmisrepresented-and-why-it-matters/.

36. Fouogue JT, Noubom M, Kenfack B, Dongmo NT, Tabeu M, Megozeu L, et al. Poor knowledge of COVID-19 and unfavourable perception of the response to the pandemic by healthcare workers at the Bafoussam Regional Hospital (West Region-Cameroon). Pan Afr Med J. 2020;37. [cited 2020 Nov 12] Available from: https://www.panafrican-med-journal.com/content/ series/37/1/19/full

37. Yao H. The more exposure to media information about COVID-19, the more distressed you will feel. Brain Behav Immun. 2020;87:167-9. https://doi.org/1 0.1016/j.bbi.2020.05.031.

38. COVID-19 Map. Johns Hopkins Coronavirus Resour. Cent. [cited 2020 Apr 15]. Available from: https://coronavirus.jhu.edu/map.html

39. Xiang Y-T, Yang Y, Li W, Zhang L, Zhang Q, Cheung T, et al. Timely mental health care for the 2019 novel coronavirus outbreak is urgently needed. Lancet Psychiatry. 2020;7(3):228-9. https://doi.org/10.1016/S2215-0366(20)3 0046-8.
40. Bakehe NP, Fambeu AH, Tamokwe Piaptie GB. Internet adoption and use in Cameroon. Cameroon: Theoretical and Applied Economics Research Group, University of Douala; 2017.

\section{Publisher's Note}

Springer Nature remains neutral with regard to jurisdictional claims in published maps and institutional affiliations.
Ready to submit your research? Choose BMC and benefit from:

- fast, convenient online submission

- thorough peer review by experienced researchers in your field

- rapid publication on acceptance

- support for research data, including large and complex data types

- gold Open Access which fosters wider collaboration and increased citations

- maximum visibility for your research: over $100 \mathrm{M}$ website views per year

At $\mathrm{BMC}$, research is always in progress.

Learn more biomedcentral.com/submissions 